\title{
The concept of instability: a French perspective on the concept of ADHD
}

\author{
Michel Bader • Nouchine Hadjikhani
}

Received: 20 May 2013/Accepted: 31 October 2013/Published online: 4 December 2013

(C) Springer-Verlag Wien 2013

\begin{abstract}
Historical references to the emergence of the current concept of ADHD typically cite descriptions from medical textbooks by Weikard (1775) and Crichton (An inquiry into the nature and origin of mental derangement: Comprehending a concise system of the physiology and pathology of the human mind and a history of the passion and their affects. Cardell Jr and Davies, Londres, 1798) on attention disorders, poems of Hoffman on hyperactive and impulsive behaviors (Der Struwwelpeter. Frankfurt am Main, Literarische Anstalt, 1843), as well as the work of Still (Lancet 1:1008-1012, 1077-1082, 1163-1168, 1902a, Lancet 159(4102):1008-1013, 1902b, Lancet 159(4103): 1077-1082, 1902c, Lancet 159(4104):1163-1168, 1902d) on impulsive behaviors and defective moral regulation of behavior. The notion of "instability" developed by French physicians between 1887 and 1910 is rarely mentioned and often ignored. Writings from this period show that in France, the emergence of the concept of ADHD according to modern terminology comes from the notion of "mental
\end{abstract}

M. Bader $(\square)$

Research Unit, Service de Psychiatrie de l'Enfant et de l'Adolescent (SUPEA), 25A Rue du Bugnon, 1011 Lausanne,

Switzerland

e-mail: bader_m@bluewin.ch

M. Bader

CHUV, Lausanne, Switzerland

N. Hadjikhani

MGH/HMS/MIT A. A. Martinos Center for Biomedical

Imaging, Charlestown, MA, USA

e-mail: nouchine@nmr.mgh.harvard.edu

N. Hadjikhani

Gillberg Neuropsychiatry Center, Sahlgrenska Academy,

University of Gothenburg, Göteborg, Sweden instability" introduced in the 1890s under the leadership of Désiré-Magloire Bourneville at the Hospital Bicêtre in Paris, based on his observations of children and adolescents who had been labeled "abnormal" and placed in medical and educational institutions. In the early twentieth century, elaborating on the observations of Bourneville, Jean Phillipe and Georges Paul-Boncour showed the presence of a subgroup of "unstable" children who suffered from a disease entity in its own right within the population of "abnormal" schoolchildren (the terminology of the time). This new pathological entity included symptoms of hyperactivity, impulsivity and inattention, corresponding to today's classic triad of ADHD symptoms. While noting the lack of behavioral inhibition, clinical descriptions of Bourneville, Philip and Paul-Boncour also considered the notion of "moral disorder" which at that time played an important role in psychopathology. This resulted in some degree of confusion between impulsive symptoms and major behavioral disturbances often associated with ADHD.

\section{Keywords ADHD $\cdot$ Instability $\cdot$ History $\cdot$ French psychiatry}

\section{Introduction}

The current concept of ADHD can find its sources in the literature of more than 200 years ago, from the descriptions in medical textbooks by Melchior Adam Weikard in 1775 and by Crichton published in 1798 on attention disorders, to those of Hoffman on hyperactive and impulsive behaviors published in 1843 («Die Geschichte von dem ZappelPhilipp»). In particular, Weikard (1775) described "poor inhibition" corresponding to current characteristics of 
ADHD and underlined the fact that inattention was more common in youth than in older people (Barkley and Peters 2012). Crichton's musings on the problems in attention (1798) were based on his earlier unspecified personal experience, but he nevertheless deserves credit in the history of disorders of attention for his thoughtful considerations about their types and etiologies, and his speculations on how the inborn or innate forms of attention might best be improved by individualized education (Lange et al. 2010; Palmer and Finger 2001; Taylor 2011). Later, George Still's work (1902a, b, c) addressed the issues of impulsivity and defective moral regulation of behavior.

The notion of "instability" developed by French physicians between 1885 and 1910 is rarely mentioned and often ignored. Writings from this period show that in France, the emergence of the concept of ADHD, according to modern terminology, comes from the notion of "mental instability" introduced in 1885 under the leadership of Désiré-Magloire Bourneville at the Hospital Bicêtre in Paris. Bourneville observed children and adolescents who had been labeled "abnormal" and placed in medical and educational institutions, and he provided the first clinical description of hyperactive and impulsive symptoms in a teenager in 1887. Charles Boulanger, a student of Bourneville, wrote the second essay about four children aged between 12 and 15 years in his 1892 thesis.

In the early twentieth century, elaborating on the observations of Bourneville, Georges Paul-Boncour and Jean Phillipe showed the presence of a subgroup of "unstable" children who suffered from a disease entity in its own right in the population of "abnormal" schoolchildren (the terminology of the time). This new pathological entity included symptoms of hyperactivity, impulsivity and inattention, corresponding to today's classic triad of ADHD symptoms. While noting the lack of behavioral inhibition, clinical descriptions of Bourneville, Paul-Boncour and Philippe also considered the notion of "moral disorder" which at that time played an important role in psychopathology. This resulted in some degree of confusion between impulsive symptoms and major behavioral disturbances often associated with ADHD.

Despite the fact that the initial descriptions of Bourneville, Paul-Boncour and Philippe had set the foundations of the current concept of ADHD, the different models of "instability" of Dupré (1913), Heuyer (1914), Wallon (1925) and Abramson (1940) have included a constellation of associated disorders fundamentally related to problems of character or personality, and not only focused on ADHD symptoms. These authors focused on the impact of immaturity of brain development linked with motor, cognitive and affective components without at this time directly relating it to Piagetian ideas of development.

"Instability" from the 1950s onwards has been understood by the great majority of French psychiatrists not only as ADHD symptoms, but in light of the semiotic principles of Freudian metapsychology, apprehending symptoms of "instability" by seeking their unconscious meaning and psychic conflicts. The impact of the psycho-analytical paradigm and the reluctance to integrate neurobiological models has led to a French idiosyncratic approach of ADHD during the second part of twentieth century.

\section{"Immoral" behaviors at the end of the nineteenth century and early twentieth century}

In the context of social changes in the nineteenth century, the middle and upper classes in Europe had become increasingly concerned about the underclass, whose behavior was described as immoral (e.g., high rates of alcoholism, crime, prostitution and poverty), and who were feared for being potentially easily radicalized by political movements (Stedman Jones 1971). The events of the Commune in 1870 had shocked French society and provided impetus for the ruling classes to implement social reform for the classes who were not benefitting from the impact of the industrial revolution. In England as well as in France, lower social classes exhibited a high infant mortality rate, and workers and army recruits were in poor health (Davin 1978). In this context, in France, a movement for the protection of children "in moral danger," especially from the years 1880-1890, was accompanied by an interest in "abnormal" children (blind, deaf and dumb, mentally retarded, epileptic and "social cases").

In parallel, the laws of France in 1882 on compulsory schooling opened the public schools to children from disadvantaged backgrounds, which forced the members of French society to confront the existence of children called "abnormal," such as the mentally retarded and "unstable," whose condition was not severe enough that it would require hospitalization or confinement in asylums. However, these children had considerable learning difficulties and/or serious behavioral problems, and their presence in public schools was considered problematic, hindering its operation and brand image (Pinel 1977).

This concern about "abnormal" children led to a process of institutionalization, with the creation of entities more suited to support the academic, medical and educational needs of this young population and the establishment of a scientific corpus to provide a sound nosographic classification (Muel-Dreyfus 1975). In this context, French doctors such as Bourneville, Paul-Boncour and Philipe stressed social issues and the role of screening "abnormal" children 
to address the moral problems (e.g., lying), in order to reduce the social impact of delinquency.

\section{The medico-pedagogical approach of "mental instability"}

The concept of "mental instability" appeared in the 1880's based on the reflections of Désiré-Magloire Bourneville, psychiatrist at Bicêtre Hospital Paris. It has great historical interest in the emergence of the nosology of ADHD in Western medicine.

Désiré-Magloire Bourneville (1840-1909) was the chief physician of the "idiot and epileptic children ward" created in 1879 at the Bicêtre Hospital in Paris. He was very involved in the medical, educational and political movement that aimed at taking children out of crowded asylums, where they were suffering from a lack of basic hygiene as well as from rampant promiscuity with adults. Bourneville's political activity as a deputy and his personal skills led him to be a member of the Supervisory Board of Insane Asylums of the Seine (Wacjman 1990). His political orientations were republican, secular and strongly anticlerical. He was a humanist inspired by Jean-Jacques Rousseau and "the ideas of the French Revolution on the organization of assistance: to assist, support, help all unfortunates: elderly, diseased, infirm of body and mind, orphans, and unemployed citizens" (Bourneville 1895; Wacjman 1990). Bourneville fought for the creation of appropriate structures for children and adolescents, in order to integrate them into more appropriate places, such as special classes attached to primary schools or in specific locations. He spent a lot of energy from 1879 to 1892 to develop and implement a section at Bicêtre Hospital separated from adults and that featured a team of caregivers and teachers for the "young boys and the idiots" (Bourneville 1892)

Following the steps of his predecessor Dr. Seguin, a pioneer of education of the mentally retarded who worked at Bicêtre in 1843, Bourneville was the initiator of a medico-pedagogical approach, a term coined by him, for the children who at the time were designated as "abnormal." These children suffered from learning disabilities often linked to intellectual disabilities (e.g., "idiots" and "imbeciles" in the terminology of the time). Bourneville had a pioneering role in the medico-pedagogical management of children and adolescents "deemed incurable" and/ or "unstable." This included well-organized and ageadapted curricula in smaller classes and practical workshops, giving rewards to "the more laborious" and having activities such as shoemaking, printing, carpentry, locksmithing, under the surveillance of nurses and teachers (Bourneville 1886a, b). Learning by direct contact with the surrounding world was one of the pedagogical axes ("lessons of things play a large role in the programs" Bourneville 1886a, b). For example, the gardens between buildings were designed to educate children and teach them about horticulture during their daily strolls, and each plant was labeled with its common and scientific name. Medical treatment combined bodily approaches (e.g., gymnastics, hydrotherapy with baths and showers) and pharmaceutical means, such as bromides, and anti scrofulous drugs like picrotoxin (Wacjman 1990). Children also participated in educational excursions (e.g., to the Botanical Garden, Conservatory of Arts and Crafts, Fair at the Place des Nations) and in recreational activities (e.g., annual concert with artists, "Magic Lantern" evenings, theater performances, distribution of toys).

Within a very heterogeneous population of children and adolescents hospitalized in his service, Bourneville observed during the 1880 s and 1890 s the presence of symptoms of "mental instability" (in his terminology) in some children, who retrospectively presented semiological features corresponding to current criteria for hyperactivity and impulsivity. Bourneville had already used the term "unstable" in an activity report of his ward at Bicêtre in 1885 , but without further clinical precision. In a paper published in 1888, he described the case of a 14-year-old boy admitted to Bicêtre in 1881 (Bourneville 1888; Thuillier 2004). This observation of an "unstable" is rigorous, subtle and rich. It paints a vivid picture of a teenager with symptoms suggestive of ADHD by today's standards, associated with severe behavioral disorders, including disorders of sexual behavior. The hyperactive and impulsive components were clearly described, and attention disorders were mentioned as well (e.g., "we cannot give him any package, he will forget it, leave it on a bench or in the omnibus" p. 349).

This report also described the positive effects of early support during childhood and the issues associated with becoming an adult, taking into account both the symptoms associated with ADHD and related disorders.

Probably following Bourneville's advice, Charles Boulanger made the second detailed description of four children and adolescents in 1892 (Boulanger 1892), described as being intelligent, but "rowdy and undisciplined." Boulanger's first case was chosen to highlight the role of mental instability "since early childhood" in the evolution of a 14 year-old boy with impulsivity problems, and behavioral difficulties with risk-taking and impulsive aggressive movements. His second case was a 15 year-old boy described as: "Turbulent and unruly; cannot remain quiet for a second; change and succession of events are the goal of his life. His attention problems are such that he could neither be at school nor in an apprenticeship. When he begins a new work he rapidly loses interest and gets 
very quickly bored by the repetitive sight of the same object" (p. 25). Recognition of his status as a patient allowed a new look at his problems and resulted in admission to Bicêtre where "he is subject to admirable exercises of the educational and hygienic treatment instituted by Dr. Bourneville." His third case emphasized the role of alcohol consumption by his father in a 12 year-old teenager's behavior, that "caused all the trouble" (p. 44), and his fourth case was about another 12 year-old teenager when he was hospitalized in Bicêtre in 1881 with a clinical observation until 20 year-old about the "hereditary weight of the parents" who had "a destructive influence on the bodies of their heirs" (p. 44). These four vignettes describe both hyperactive and impulsive behaviors as well as conduct disorders or major oppositional defiant disorders according to current diagnostic classifications. The considerable difficulties in integrating social rules are described as "perversions of instincts." It should be noted that the second vignette also mentions the presence of attention problems, not included in the other three cases.

Besides cases of "idiocy" or "imbecility," Boulanger, following Bourneville's ideas, proposed to distinguish a new category of patients with normal intelligence, the "unstables," a concept that includes several clinical features that correspond to the current concept of ADHD. These patients had the following characteristics: "Some only show a lack of balance in the faculties of the mind. They cannot fix their attention for a long period; they have no attachment; they must act differently than others. They are intelligent, but their repeated inconsistencies and their continuous eccentricities draw attention to them. It seems that some unknown power pushes them periodically to strange behaviors that they cannot justify for people around them" (pp. 8-9).

In a letter to the Director of Education of the Seine dated from November 5th 1896, Bourneville proposed a classification that contained: absolute idiocy, profound idiocy, imbecility itself, mental retardation and mental instability. Descriptions of unstable children have very interesting features compared with the current concept of ADHD: "The unstable have exuberant physical mobility. They never stay still, they get up from the table at any time without cause. When they are playing, they quickly move from one game to another. Their intellectual mobility is not reduced. Hardly have they started reading when they want to write or count, etc. They do not obey. Problems are similar with manual labor. Shortly after starting in the apprenticeship in a profession that they have chosen themselves, they want to change, trying one after the other in a series of different professions, without ever without ever making a final choice. They have sudden impulses, escape from school, from their parent's house, wander for more or less time, and return back home either spontaneously or because they were arrested by the police. They are prodigal of promises, often in good faith with their intention at the time to keep them, but a few hours or minutes later they perform what they just promised not to do."

As for George Still (Lange et al. 2010; Taylor 2011), Bourneville's clinical approach was also very influenced by the exceedingly important concept of moral issues prevalent at that time (e.g., the child with "perverse instinct"). Particular attention was then paid to children's "moral sense," in a view very close to that of the church moralists (Pinel 1977, p. 348), which influenced the clinical descriptions (e.g., the "unruly") and the understanding of the behavioral problems of children and adolescents for several decades in France. As noted by Pinel, a very important place was also made for the study of social environment, especially of the familial environment, from a hereditary and educational point of view (e.g., parents without "morality," or "vicious environment").

In their book The Mental Abnormalities in Schoolchildren (1905), Paul-Boncour and Philippe referred to the classification proposed in 1896 by Bourneville and questioned the existence of an "essential instability" in children without mental retardation or idiocy. Their descriptions of unstable schoolchildren are very interesting in light of today's ADHD criteria: "mentally abnormal children, who cannot fix their attention either to listen, to answer or to understand... Perpetually, against their own will, their mind turns elsewhere and it is often noted that their physical instability is as pronounced as their mental instability" (p. 45). Some of these children had excessive nervousness: "irritable, angry, aggressive, children who get upset with no reason" (p. 45), while others were "impulsive": "irritable, crying for no reason, perpetually impatient, forced to immediately realize any idea that crosses their mind without considering the consequences" (p. 45). These unstable children with significant impulsivity created significant issues in class: "they speak loudly and carry out all the ideas that come to their mind without worrying about any supervision; they respond rudely and use insulting words at the slightest comment, sometimes even without reason" (p. 48).

Both doctors also identified attention problems: “... one can never be sure that they are aware. Their attention occurs randomly on any occasion and suddenly disappears, so that the teacher sees this pupil who a minute ago was attentive to all that he was seeing and hearing, now a moment later seems to be totally estranged to his simple teaching as if he were retarded. One could think that he came to class for anything but to listen" (p. 47).

In their 1910 book The Education of Abnormal, PaulBoncour and Philippe mentioned once more attention problems in unstable children as follows: "their actions 
seem to follow no logic. One activity succeeds another; when one tries to entice them to work, their inattention is remarkable" (1910, p. 8). The essence of inattention was finely described by these authors: "The inability to switch from spontaneous and passive attention to reflected and desired attention"; "the unstable know almost no other form of attention than that imposed from outside; unable to self-govern their own state of attention, they can only be subjected to the facts" (1910, p. 148). Their descriptions also included some interesting observations on issues related to executive functions in daily life (e.g., "the least affected simply fail in the details of everyday schooling: disorder in homework, notebooks poorly maintained, lack of plans, irregularity in the distribution and follow-up of homework, etc." (1910, p. 151).

In continuation of Bourneville's ideas, Paul-Boncour and Philippe underlined the importance of a therapeutic approach combining both medical and educational aspects during the child's physical and mental development, in order to restore balance and favorably influence their future (1905, p. 50).

The concept of "mental instability" developed under the leadership of Bourneville and then identified as a disorder by Paul-Boncour and Philip involved children and adolescents who, according to our current criteria, would correspond to a diagnosis of ADHD with the frequent presence of behavioral comorbidities such as oppositional defiant disorder or conduct disorder. It is interesting to note that these physicians also described the impact on these "unstable" subjects of their difficulties during childhood and adolescence, and even in adulthood. Bourneville and Paul-Boncour were convinced of the organic origin of these symptoms reflecting cerebral dysfunctions and pathologies.

\section{Following contributions in the French tradition}

The next contributions, conceived in the French tradition, made continued reference to the notion of "instability," while providing additional perspectives.

After the 1882 law of compulsory education, Binet was appointed in 1904 by the minister of Education to develop a tool that would identify children likely to experience the greatest difficulty in school. Alfred Binet, psychologist, partnered with Theodore Simon, physician, to develop a psychometric scale in order to make a rapid diagnosis of mental retardation, and to assess the performance of "abnormal children" by comparing their performance those of the same age-range. Descriptions of "unstable" children of Binet and Simon (1907) were based on Bourneville's observations, and failed to sufficiently distinguish specific aspects of "instability," also giving significant weight to the character and moral components.
Their psychometric scale allowed Binet and Simon to realize that intellectually, the "unstables" were doing better than the "retards," but worse than normal children, with a delay at school of about a year on average. Remarkably, they noted the positive consequences of an encouraging and supportive attitude toward these children (e.g., praises when their behavior is appropriate, or entrusting them with small responsibilities). These authors also reported the possibility of favorable outcome when these children could benefit from a specialized teaching.

The next step was the concept of "restlessness" proposed in the 1910s by Ernest Dupré, that according to him reflected a "congenital motor imbalance," based on a close relationship "between movement and thought," i.e., between the motor and psychic dimensions. Henri Wallon further developed this hypothesis in 1920, and distinguished three types of instability (asymmetric, epileptoid and subchoreic), based on a neurological understanding of the symptoms. Later, in 1940, Jadigwa Abramson performed a study on 1,117 children with instability investigated between 1926 and 1928 in Paris. She proposed a model of restlessness, which reflected an imbalance in the motor, intellectual and emotional development of the child. Abramson has also described the effect of autoregulation dysfunction in children with instability according to recent hypotheses of Barkley (2009). Georges Heuyer (1914) investigated behavioral problems, which had replaced "instability" as the label for the behavior associated with this disease, focusing his attention on the problems of social maladjustment and severe behavioral disorders. The symptoms of "instability" were considered part of a constellation of associated disorders fundamentally related problems of character or personality.

"Instability" from the 1950s onwards has been understood by the great majority of French psychiatrists in light of the semiotic principles of the psychoanalytic paradigm, apprehending symptoms of "instability" by seeking by seeking their unconscious meaning and psychic conflicts. All neurobiological dimensions have been either simply disregarded, or barely taking into account, and most psychiatrists have even been opposing approaches which attempted to connect descriptive accounts of symptoms with brain functioning and their international classifications. However, since 2000, the possibility of a multidimensional understanding of ADHD has started to emerge in French-speaking countries that more appropriately accounts for the neurobiological components and for the new therapeutic approaches to this disorder.

\section{Conclusions}

Still's descriptions in his three lectures have been an important milestone in the development of the concept of 
ADHD, although he was mostly focused on attentional issues and associated disorders, including response inhibition and emotional self-regulation problems. However, the French doctors Bourneville, Paul-Boncour and Philippe, who were all Still's contemporaries, contributed to a more complete illustration of the characteristics of ADHD in different contexts than that of Still and provided remarkable and detailed written observations of the symptoms belonging to the current concept of ADHD. They proposed a multidimensional support model of "unstable" children who for a large part corresponded to the current concept of ADHD. Like Still, these doctors were great clinicians, but they probably had responsibilities that lead them to be more involved in the daily care of these children, in school or institutional contexts.

For these reasons, the concept of "instability" introduced by French physicians between 1885 and 1910 should be included in the referenced historical contributions to the emergence of the syndrome of ADHD, to the same extent as Still's three lectures.

\section{References}

Abramson J (1940) L'enfant et l'adolescent instables: études cliniques et psychologiques. Presses Universitaires de France, Paris

Arch. I.P.N., dossier II3, projet de loi ayant pour objet la création de classes et d'écoles de perfectionnement pour les enfants anormaux, présenté à la chambre des députés en 1907

Barkley RA (2006) The relevance of the Still lectures to attentiondeficit/hyperactivity disorder: a commentary. J Atten Disord 10(2):137-140. doi:10.1177/1087054706288111

Barkley RA (2008) Commentary on excerpt of Crichton's chapter, on attention and its diseases. J Atten Disord 12(3):205-206

Barkley RA (2009) Deficient emotional self-regulation: a core component of attention-deficit/hyperactivity disorder. J ADHD Relat Disord 1:5-37

Barkley RA, Peters H (2012) The earliest reference to ADHD in the medical literature ? Melchior Adam Weikard's description in 1775 of "Attention Déficit" (Mangel der Aufmerksamkeit, Attention Volubilis). J Atten Disord 16(8):623-630. doi:10. 1177/1087054711432309

Binet A, Simon T (1907) Les enfants anormaux. Guide pour l'admission dans les classes de perfectionnement. Colin, Paris

Boulanger C (1892) Contribution à l'étude de l'instabilité mentale. Thèse pour le Doctorat en Médecine. Paris, Imprimerie de la Faculté de Médecine

Bourneville DM (1886a) Recherches cliniques et thérapeutiques sur l'épilepsie, l'hystérie et l'idiotie. Compte rendu du service des épileptiques et des enfants idiots et arriérés de Bicêtre pendant l'année 1885. Le Progrès Médical. Tome V

Bourneville DM (1886b) Recherches cliniques et thérapeutiques sur l'épilepsie, l'hystérie et l'idiotie: Compte-rendu du service des épileptiques et des enfants idiots et arriérés de Bicêtre pendant l'année 1885 In: Lecrosnier (ed) Paris

Bourneville DM (1887) Recherches cliniques et thérapeutiques sur l'épilepsie, l'hystérie et l'idiotie. Compte rendu du service des épileptiques et des enfants idiots et arriérés de Bicêtre pendant l'année 1886. Le Progrès Médical, Tome VI
Bourneville DM (1888) Imbécillité légère, instabilité mentale avec perversion des instincts et impulsions génitales (Kleptomanie, onanisme, sodomie, syphillis). Recherches cliniques et thérapeutiques sur l'épilepsie et l'idiotie pour 1888. Paris, Publications du Progrès Médical, E. Lecrosnier et Babé (Eds, 1889)

Bourneville DM (1892) Histoire de la section des enfants de Bicêtre, 1879-1892. Publications du Progrès Médical, Paris

Bourneville DM (1895) Assistance, traitement et éducation des enfants idiots et dégénérés (Rapport fait au Congrès national d'assistance publique, Session de Lyon, 1894). Bibliothèque d'éducation spéciale, t. IV, Paris, Publications du Progrès Médical

Bourneville DM (1897) Lettre aux membres de la 3ème Commission du Conseil Général de la Seine sur la création de classes spéciales pour les enfants arriérés, Bicêtre, imprimerie des enfants (Lettre datée du 10 décembre 1896)

Bourneville DM (1905) Traitement medico-pédagogique des différentes formes de l'idiotie. Publications du Progrès Médical, Paris

Crichton A (1798) An inquiry into the nature and origin of mental derangement: comprehending a concise system of the physiology and pathology of the human mind and a history of the passion and their affects. Cardell Jr and Davies, Londres

Davin A (1978) Imperialism and motherhood. Hist Workshop 5(1):9-65

Duché DJ (1990) Histoire de la psychiatrie française. Presses Universitaires de France, Paris

Dupré E (1913) Débilité et désiquilibration motrices. Paris Médical $11: 438-446$

Faure M-R (2003) La photographie scientfique de Bourneville. Communication et langages 135:104-124

Heuyer G (1914) Enfants anormaux et délinquants juvéniles: nécessité de l'examen psychiatrique des écoliers: G. Steinheil

Hoffmann H (1843) Der Struwwelpeter. Frankfurt am Main, Literarische Anstalt

Lange KW, Reichl S, Lange KM, Tucha L, Tucha O (2010) The history of attention deficit hyperactivity disorder. ADHD Atten Deficit Hyperact Disord 2:241-255

Muel-Dreyfus F (1975) L'école obligatoire et l'intervention de l'enfance anormale. Actes de la recherche en sciences sociales $1(1): 60-74$

Nigg JT (2001) Is ADHD a disinhibitory disorder? Psychol Bull 127(5):571-598

Palmer ED, Finger S (2001) An early description of ADHD (inattentive subtype): Dr Alexander Crichton and 'Mental Restlessness' (1798). Child Adolesc Ment Health 6(2):66-73

Paul-Boncour G (1912) Excitabilité psychomotrice et troubles digestifs chez l'enfant. Progrès Médical

Philippe J, Paul-Boncour G (1905) Les anomalies mentales chez les écoliers. F. Alcan, Paris

Philippe J, Paul-Boncour G (1910) L'éducation des anormaux: principes d'éducation physique, intellectuelle, morale. Alcan, Paris

Pichot P (1996) Un siècle de psychiatrie. Les Empêcheurs de penser en rond, Synthélabo, Paris

Pinel P (1977) L'école obligatoire et les recherches en psychopédagogie au début du XXe siècle. Cahiers internationaux de sociologie 63:341-362

Schachar RJ (1986) Hyperkinetic syndrome: historical development of the concept. In: Taylor IE-A (ed) The overactive child. Lippincott, Philadelphia, pp 19-40

Stedman Jones G (1971) Outcast London: study in the relationship between classes in victorian society. Oxford University Press, Oxford

Still G (1902a) The Goulstonian lectures on some abnormal psychical conditions in children. Lancet 159(4102):1008-1013. doi:10. 1016/s0140-6736(01)74984-7 
Still G (1902b) The Goulstonian lectures on some abnormal psychical conditions in children. Lancet 159(4103):1077-1082. doi:10. 1016/s0140-6736(01)70022-0

Still G (1902c) The Goulstonian lectures on some abnormal psychical conditions in children. Lancet 159(4104):1163-1168. doi:10. 1016/s0140-6736(01)74901-X

Taylor E (2011) Antecedents of ADHD: a historical account of diagnostic concepts. Atten Deficit Hyperact Disord 3:69-75

Thuillier G (2004) Une observation de Bourneville sur un enfant instable. Bulletin d'histoire de la sécurité sociale, 49:340-350
Vial M, Huguon MA (1998) La Commission Bourgeois (1904-1905). Documents pour l'histoire de l'éducation spécialisée. Éditions du CTNERHI, Paris

Wacjman C (1990) Désiré Magloire Bourneville dans le grand centenaire de la Révolution. L’Évolution psychiatrique 55(1):179-191

Wallon H (1925) L'Enfant turbulent: étude sur les retards et les anomalies du développement moteur et mental. Alcan, Paris

Weikard MA (1775) Der Philosophische Arzt, Frankfurt 